\title{
Synergistic Effect of Nizoral and Iodide Ions on the Corrosion Inhibition of Mild Steel in Sulphuric Acid Solution
}

\author{
Ime B. Obot* \\ ${ }^{1}$ Department of Chemistry, Faculty of Science, University of Uyo, Uyo, Nigeria
}

Received 13 February 2009; accepted 21 October 2009

\begin{abstract}
The corrosion rates in the presence of nizoral (NZR), an antifungal drug, as mild steel corrosion inhibitor in $0.1 \mathrm{M} \mathrm{H}_{2} \mathrm{SO}_{4}$ was measured by the weight loss method in the temperature range from $30-50{ }^{\circ} \mathrm{C}$. Results obtained revealed that NZR acts as an inhibitor for mild steel in sulphuric acid solution. Inhibition efficiency increased with increase in concentration of the inhibitor but decreased with increase in temperature. The addition of KI increased the inhibition of NZR to a considerable extent. The experimental results suggest that the presence of iodide ions in the solution stabilized the adsorption of Nizoral molecules on the mild steel surface thereby improving the inhibition efficiency of Nizoral. The adsorption characteristics of the inhibitor were approximated by Langmuir adsorption isotherm and kinetic/thermodynamic adsorption model of El-Awady et al. Mechanism of physical adsorption is proposed from the activation and thermodynamic parameters calculated.
\end{abstract}

Keywords: nizoral, mild steel, corrosion inhibition, adsorption isotherm, thermodynamics, sulphuric acid.

\section{Introduction}

The corrosion process of mild steel pipelines in gas and oilfield mining induced by the presence of carbon dioxide, acid and water, has been reported to be a serious economical and environmental problem in the oil and gas industries for decades [1]. In an effort to combat this menace, corrosion inhibitors become important. The use of corrosion inhibitors has considerably increased in recent years due to increase awareness of corrosion worldwide. Compounds containing nitrogen, oxygen, sulphur and phosphorus in the conjugated system have particularly been reported as efficient corrosion inhibitors [2-8]. It is generally believed that corrosion inhibitors effectively eliminate the undesirable

\footnotetext{
* Corresponding author. E-mail address: proffoime@yahoo.com
} 
destructive effects of aggressive media and prevent steel dissolution. The inhibitive action of inhibitors is usually attributed to their interactions with the steel surface via their adsorption [9]. However, the adsorption of an inhibitor on a metal surface depends on the nature as well as the surface charge of the metal, the adsorption mode, its chemical structure, and the type of the electrolyte solution [10].

Co-adsorption of two or more molecules otherwise called synergistic effects on the inhibitors describes the enhancement of the performance of a corrosion inhibitor in the presence of another substance in small quantity in the corrosive medium. This phenomenon can be thought of as an effective method of getting better performance or to decrease the amount of usage of the inhibitor [11]. It is generally accepted that the presence of halide ions in acidic medium synergistically increases the inhibition efficiency of some organic compounds. Previous reports have shown that the inhibiting effect of halide ions in combination with organic compounds in acidic medium increases in the order $\mathrm{I}^{-}$ $>\mathrm{Br}^{-}>\mathrm{Cl}^{-}$[12-15]. The greater influence of the iodide ion is often attributed to its large ionic radius, high hydrophobicity, and low electronegativity, compared to other halide ions.

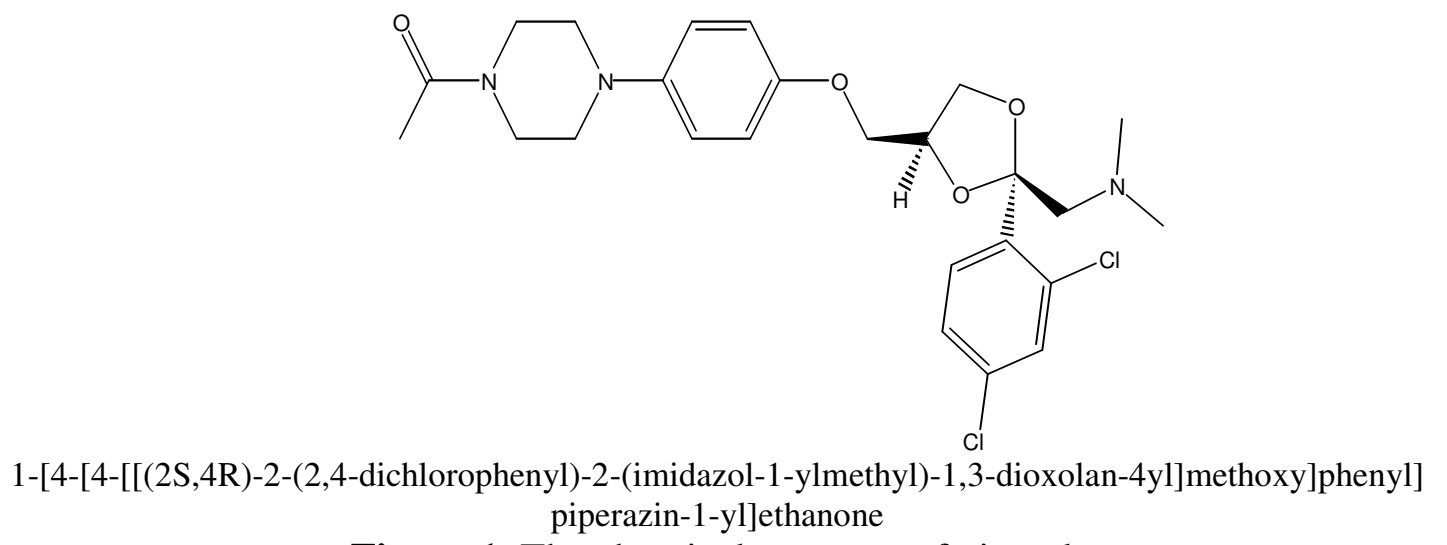

Figure 1. The chemical structure of nizoral.

Recently, there have been some reports on the use of drugs as corrosion inhibitors for metals in various media [16-31], but the synergistic effect of iodide ion addition on the performance of such drugs may not have been explored at all. Therefore, the present work is aimed at investigating the possible enhancement of inhibition efficiency of an antifungal drug, nizoral (NZR) in the presence of iodide ions on mild steel corrosion in $\mathrm{H}_{2} \mathrm{SO}_{4}$ using gravimetric technique at 30$50{ }^{\circ} \mathrm{C}$, and to propose a suitable mechanism for the synergistic inhibitory action. As a drug, nizoral was found to be a heterocyclic compound containing $\mathrm{O}, \mathrm{N}$ atoms and $\pi$ bonds that are regarded as important factors for a good inhibitor. Besides, nizoral is very cheap, easily available, and the most important, nontoxic. Furthermore, NZR has a large molecular size (molecular weight 508.4) and likely to effectively cover more surface area (due to adsorption) of the mild steel metal. 


\section{Experimental}

\section{Specimen preparation}

Chemical composition of mild steel samples is shown in Table 1. Specimens used in the weight loss experiment were mechanically cut into $5.0 \mathrm{~cm} \times 4.0 \mathrm{~cm} \times$ $0.8 \mathrm{~cm}$ dimensions, then polished with $\mathrm{SiC}$ abrasive papers 320, 400 and 600 grit, respectively, washed in absolute ethanol and acetone, dried at room temperature and stored in a moisture free dessicator before their use in corrosion studies.

Table 1. Chemical composition of mild steel samples (wt. \%).

\begin{tabular}{|c|c|c|c|}
\hline $\mathrm{C}$ & 0.19 & $\mathrm{Cr}$ & 0.08 \\
\hline $\mathrm{Si}$ & 0.26 & $\mathrm{Mo}$ & 0.02 \\
\hline $\mathrm{Mn}$ & 0.64 & $\mathrm{Cu}$ & 0.27 \\
\hline $\mathrm{P}$ & 0.06 & $\mathrm{Fe}$ & Bal. \\
\hline $\mathrm{S}$ & 0.05 & \multicolumn{2}{|c}{} \\
\cline { 1 - 3 } & \multicolumn{2}{|l}{}
\end{tabular}

\section{Test solutions preparation}

$0.1 \mathrm{M} \mathrm{H}_{2} \mathrm{SO}_{4}$ solution was prepared by dilution of $97 \% \mathrm{H}_{2} \mathrm{SO}_{4}$ (analytical grade) using bidistilled water. The concentration range of nizoral employed were $2 \times 10^{-5}$ - $1 \times 10^{-4} \mathrm{M}$ and the solution in the absence of NZR was taken as blank for comparison. The acid solution used for each test was freshly prepared and not deaerated before used. The halide salt, potassium iodide (KI, BDH) used was in the concentration range $1 \times 10^{-3}-5 \times 10^{-3} \mathrm{M}$. However, $5 \times 10^{-3} \mathrm{M}$ KI was used for the synergistic study.

\section{Weight loss experiment}

The apparatus and procedure followed for weight loss method was similar to that earlier reported [11]. The progress of the corrosion reaction was monitored by determining the weight loss of the specimens (obtained as the differences in the weight of the specimens after immersion in $100 \mathrm{~mL}$ of different solutions of the system and the original weight of the specimens) for $24 \mathrm{hrs}$ progressively for 7 days $(168 \mathrm{hrs})$ at $30-50{ }^{\circ} \mathrm{C}$. The temperature was controlled using a thermostated bath (Kottermann). After that, the specimens were removed, washed by immersion in $20 \% \mathrm{NaOH}$ containing $200 \mathrm{~g} / \mathrm{L}$ of $\mathrm{Zn}$ dust, scrubbed with bristle brush in deionised water and dried in fast evaporating solvent such as acetone, and finally dried in a dessicator [32]. The loss in weight was determined using an analytical balance.

\section{Results and discussion}

\section{Gravimetric measurements}

The corrosion of mild steel in $0.1 \mathrm{M} \mathrm{H}_{2} \mathrm{SO}_{4}$ solution in the absence and presence of KI, NZR and NZR - KI mixtures was investigated at temperature range 30 $50{ }^{\circ} \mathrm{C}$ using weight loss measurements.

The corrosion rate of mild steel was determined by using the equation: 


$$
W=\frac{\Delta m}{S t}
$$

where $\Delta m$ is the mass loss $(\mathrm{mg}), \mathrm{S}$ is the total surface area of the mild steel $\left(\mathrm{cm}^{2}\right)$ and $t$ is the immersion period in (h).

The percentage inhibition efficiency (I \%) was calculated using the relationship:

$$
I \%=\left(1-\frac{W_{i}}{W_{o}}\right) 100
$$

where $\mathrm{W}_{\mathrm{i}}$ and $\mathrm{W}_{\mathrm{o}}$ are the weight losses of mild steel in inhibited and unhibited solution, respectively. The degree of surface coverage $(\theta)$ was obtained from eq. (3):

$$
\theta=\left(1-\frac{W_{i}}{W_{o}}\right)
$$

Table 2 gives the values of the corrosion rate $\left(\mathrm{mg} \mathrm{cm}^{-2} \mathrm{~h}^{-1}\right)$, inhibition efficiency $(\mathrm{I} \%)$ and surface coverage $(\theta)$ for mild steel corrosion in $0.1 \mathrm{H}_{2} \mathrm{SO}_{4}$ (blank) and in the presence of inhibitor (NZR), $5 \times 10^{-3} \mathrm{M} \mathrm{KI}$ and $5 \times 10^{-3} \mathrm{M}$ KI in combination with different concentrations of NZR at $30-50{ }^{\circ} \mathrm{C}$. The results show that corrosion rates increase with increase in temperature for all the systems studied. The highest corrosion rate $\left(285.7 \times 10^{-3} \mathrm{mg} \mathrm{cm}^{-2} \mathrm{~h}^{-1}\right)$ was obtained at $50{ }^{\circ} \mathrm{C}$. In the presence of NZR and $5 \times 10^{-3} \mathrm{M} \mathrm{KI}$, the corrosion rate was observed to reduce significantly, indicating that NZR actually inhibited the corrosion of mild steel in the acidic environment. Further reduction in corrosion rate was observed on addition of $5 \times 10^{-3} \mathrm{M}$ KI to NZR. The reduction in corrosion rate of steel in the presence of NZR when combined with iodide ions was found to be concentration dependent.

Table 2. Calculated values of corrosion rate $\left(\mathrm{mg} \mathrm{cm}^{-2} \mathrm{~h}^{-1}\right)$, inhibition efficiency (I\%) and the degree of surface coverage $(\theta)$ for mild steel corrosion in $0.1 \mathrm{M} \mathrm{H}_{2} \mathrm{SO}_{4}$ for different systems at $30-50{ }^{\circ} \mathrm{C}$ from weight loss measurements.

\begin{tabular}{|l|c|c|c|c|c|c|c|c|c|}
\hline Systems/concentration & \multicolumn{6}{|c|}{ Corrosion rate $\left(\mathrm{mg} \mathrm{cm}^{-2} \mathrm{~h}^{-1}\right) \times 10^{-3},(\mathrm{I} \%)$ and $(\theta)$} \\
\hline & \multicolumn{3}{|c|}{$30^{\circ} \mathrm{C}$} & \multicolumn{3}{c|}{$40{ }^{\circ} \mathrm{C}$} & \multicolumn{3}{c|}{$50{ }^{\circ} \mathrm{C}$} \\
\hline Blank & 175.0 & - & - & 255.0 & - & - & 285.7 & - & - \\
\hline $0.005 \mathrm{M} \mathrm{KI}$ & 135.0 & 22.8 & 0.23 & 225.0 & 11.7 & 0.12 & 260.0 & 9.8 & 0.09 \\
\hline $1 \times 10^{-4} \mathrm{M}$ NZR & $130.1^{\mathrm{a}}$ & $25.6^{\mathrm{b}}$ & $0.26^{\mathrm{c}}$ & 212.5 & 16.7 & 0.17 & 243.2 & 14.9 & 0.15 \\
\hline $2 \times 10^{-5} \mathrm{M}$ NZR + KI & 116.4 & 33.5 & 0.34 & 169.1 & 33.7 & 0.34 & 196.7 & 31.2 & 0.31 \\
\hline $4 \times 10^{-5} \mathrm{M}$ NZR + KI & 100.3 & 42.7 & 0.43 & 164.3 & 35.6 & 0.36 & 188.0 & 34.2 & 0.34 \\
\hline $6 \times 10^{-5} \mathrm{M}$ NZR + KI & 87.2 & 50.2 & 0.50 & 136.9 & 46.3 & 0.46 & 157.0 & 45.0 & 0.45 \\
\hline $8 \times 10^{-5} \mathrm{M}$ NZR + KI & 73.2 & 58.2 & 0.58 & 121.1 & 52.5 & 0.53 & 146.1 & 48.9 & 0.49 \\
\hline $1 \times 10^{-4} \mathrm{M}$ NZR + KI & 63.4 & 63.7 & 0.64 & 116.7 & 54.2 & 0.54 & 141.1 & 50.6 & 0.51 \\
\hline
\end{tabular}

Notes: $\mathrm{a}=$ corrosion rate, $\mathrm{b}=$ inhibition efficiency, and $\mathrm{c}=$ degree of surface coverage.

The inhibition efficiency was found to increase with increasing concentration of NZR up to $1 \times 10^{-4} \mathrm{M}$. It was also noted to decrease with rising temperature. Addition of iodide ions further increased the inhibition efficiency values. The 
highest inhibition efficiency of $63.7 \%$ was obtained when NZR was combined with iodide ions at $30{ }^{\circ} \mathrm{C}$ (Table 2). One possible mechanism of inhibition action of inhibitors as reported by Umoren and Ebenso [33] is the adsorption of the inhibitor onto the metal surface, which blocks the metal surface and does not permit the corrosion process to take place. Nizoral is an heterocyclic compound with heteroatoms such as oxygen and nitrogen, which can serve as centres of adsorption. The $\pi$-electrons systems of NZR can possibly overlap with vacant $d-$ orbitals of the surface of the iron, resulting in a strong $d \pi$-p $\pi$ interaction. Therefore, the adsorption of NZR on mild steel may primarily be adsorption by interaction between the lone pairs of the electron of the oxygen and nitrogen atoms, respectively, on the NZR moiety and mild steel or through $\mathrm{d} \pi$-p $\pi$ interaction which is further assisted by synergism provided by $\mathrm{SO}_{4}{ }^{2-}$ and other ions present in solution [33].

In addition to the molecular form, NZR can be present in protonated form in acidic solution. The formation of positively charged protonated species facilitates adsorption of the compound on the metal surface through electrostatic interaction between the organic molecules and the metal surface [34]. It has been documented that the inhibiting effect of halide ions in combination with organic compounds in acidic medium increases in the order $\mathrm{I}^{-}>\mathrm{Br}^{-}>\mathrm{Cl}^{-}$which seems to indicate that the radii (which increases in the order $\mathrm{Cl}^{-}<\mathrm{Br}^{-}<\mathrm{I}^{-}$) of the halogens may have an important role to play in the adsorption [35]. The observed synergistic effect between NZR and $\mathrm{I}^{-}$may be attributed to the strong chemisorption of iodide ions on the metal surface. The organic cation is then adsorbed by columbic attraction on the metal surface where iodide ions are already adsorbed by chemisorptions. Further investigation on the actual reactive centers responsible for the adsorption of NZR on the mild steel surface using quantum chemical calculation, Fourier Transform Infrared Spectroscopy (FT-IR) and UV-Visible spectroscopy is ongoing in our laboratory and will be reported shortly.

\section{Adsorption consideration}

Generally, four types of adsorption may take place involving organic molecules at the metal solution interface [36], namely: (i) the electrostatic attraction between charged molecule and the charged metal; (ii) interaction of unshared electron pairs in the molecules with the metal; (iii) interaction of p-electrons with the metals; and (iv) combination of (i) to (iii). Inhibition efficiency depends on several factors, such as the number of adsorption sites and their charge density, molecular size, heat of hydrogenation, mode of interaction with the metal surface and the formation of metallic complexes [37]. Due to adsorption, inhibitor molecules block the reaction sites and reduce the rate of corrosion reaction [38]. According to the mechanism proposed by Bockris and Drazic [40], the inhibition of an inhibitor on the mild steel surface could be explained by Fe-(Inh) ads reaction intermediated as below and reported elsewhere [23]: 


$$
\mathrm{Fe}+\mathrm{Inh} \leftrightarrows(\mathrm{Inh})_{\mathrm{ads}} \leftrightarrows \mathrm{Fe}^{\mathrm{n}+}+\mathrm{ne}^{-}+\mathrm{Inh}
$$

The adsorbed layer combats the action of sulphuric acid solution and enhances protection of the metal surface [41]. When there is sufficient Fe (Inh) ads to cover the metal surface (if the inhibitor concentration is low or the adsorption rate is slow), metal dissolution would take place at sites on the mild steel surface which are free of $\mathrm{Fe}$-(Inh) $)_{\text {ads. }}$ With high inhibitor concentration, a compact and coherent inhibitor film lays over the mild steel surface, reducing chemical attack on the metal. The adsorption of an organic molecule on the surface of the mild steel is regarded as a substitution of the adsorption process between the organic compound in the aqueous phase $\left(\mathrm{Org}_{\mathrm{aq}}\right)$ and the water molecules adsorbed on the mild steel surface $\left(\mathrm{H}_{2} \mathrm{O}_{\text {ads }}\right)$ :

$$
\operatorname{Org}_{\mathrm{aq}}+\mathrm{xH}_{2} \mathrm{O}_{\mathrm{ads}} \leftrightarrows \mathrm{Org}_{\mathrm{ads}}+\mathrm{x}_{2} \mathrm{O}_{\mathrm{aq}}
$$

where $\mathrm{x}$ is the ratio size in terms of the number of water molecules replaced by the adsorbed molecules. When the equilibrium of the process described in the above equation is reached, it is possible to obtain different expression of the adsorption isotherm plots.

Adsorption isotherms are very important in understanding the mechanism of organo-electrochemical reactions [8]. In discussing adsorption isotherms, the degrees of surface coverage $(\theta)$ values were obtained from weight loss measurements using equation (3). Attempts were made to fit ' $\theta$ ' values to the Thermodynamic-kinetic model of El-Awady et al. Freundlich, Temkin and Langmuir isotherms and correlation coefficient $\left(\mathrm{R}^{2}\right)$ values were used to determine the best fitted isotherm. By far, best results were obtained for Thermodynamic-kinetic model of El-Awady model and Langmuir adsorption isotherm.

The surface coverage values for NZR and NZR + iodide mixture were fitted into Langmuir adsorption isotherm model, which has the form:

$$
\frac{C}{\theta}=\frac{1}{K}+C
$$

where $\theta$, is the degree of surface coverage, ' $\mathrm{K}$ ' is the equilibrium constant of adsorption process and ' $C$ ' is the concentration of the inhibitor. The plot of $C$ / $\theta$ versus $\theta$ is shown in Figs. 2 and 3 (Langmuir adsorption isotherm). From the plot (Figure 3) straight lines were obtained with $\mathrm{R}^{2}>0.9$ for all the systems studied, indicating that the experimental data fit well into Langmuir adsorption isotherm. None of the plots have slope equal to unity. Such deviations from unity may be attributed to the interaction between the adsorbed molecules on the metal surface and changes in the values of the heat of adsorption with increasing surface coverage [39]. Thus, the adsorption data generally will be more 
appropriately described by a modified equation taking the above factors into consideration. Such a modified Langmuir isotherm has been reported elsewhere [42]:

$$
\frac{C}{\theta}=\frac{n}{K_{a d s}}+n C
$$

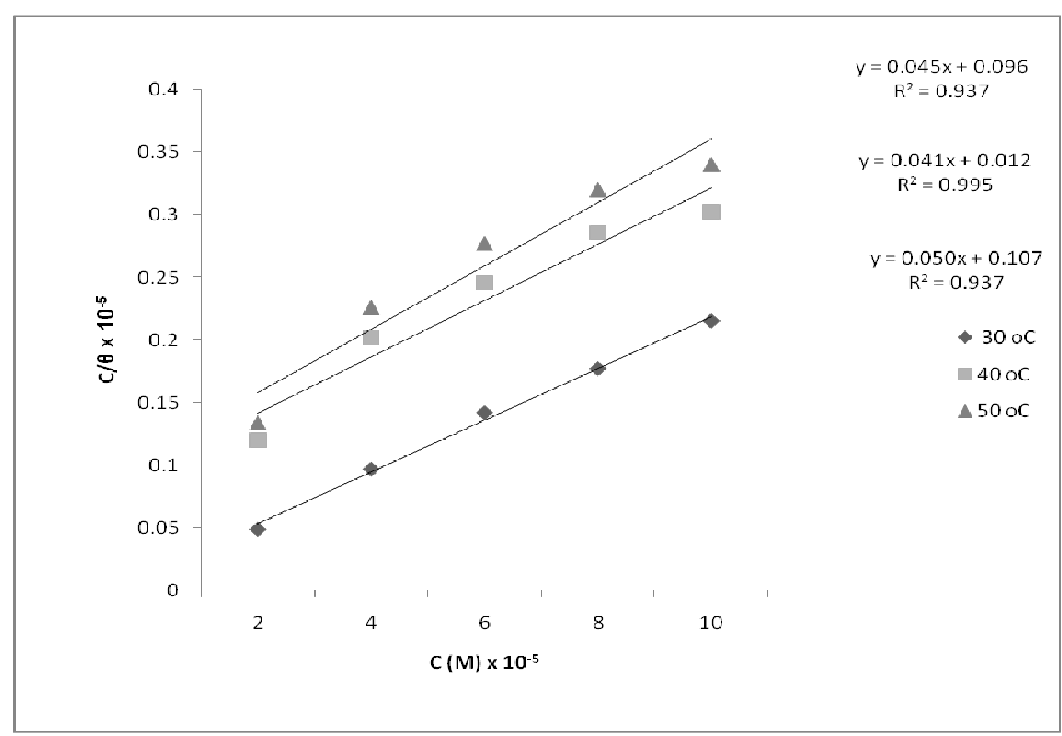

Figure 2. Langmuir adsorption isotherm plot for nizoral at 30,40 and $50{ }^{\circ} \mathrm{C}$.

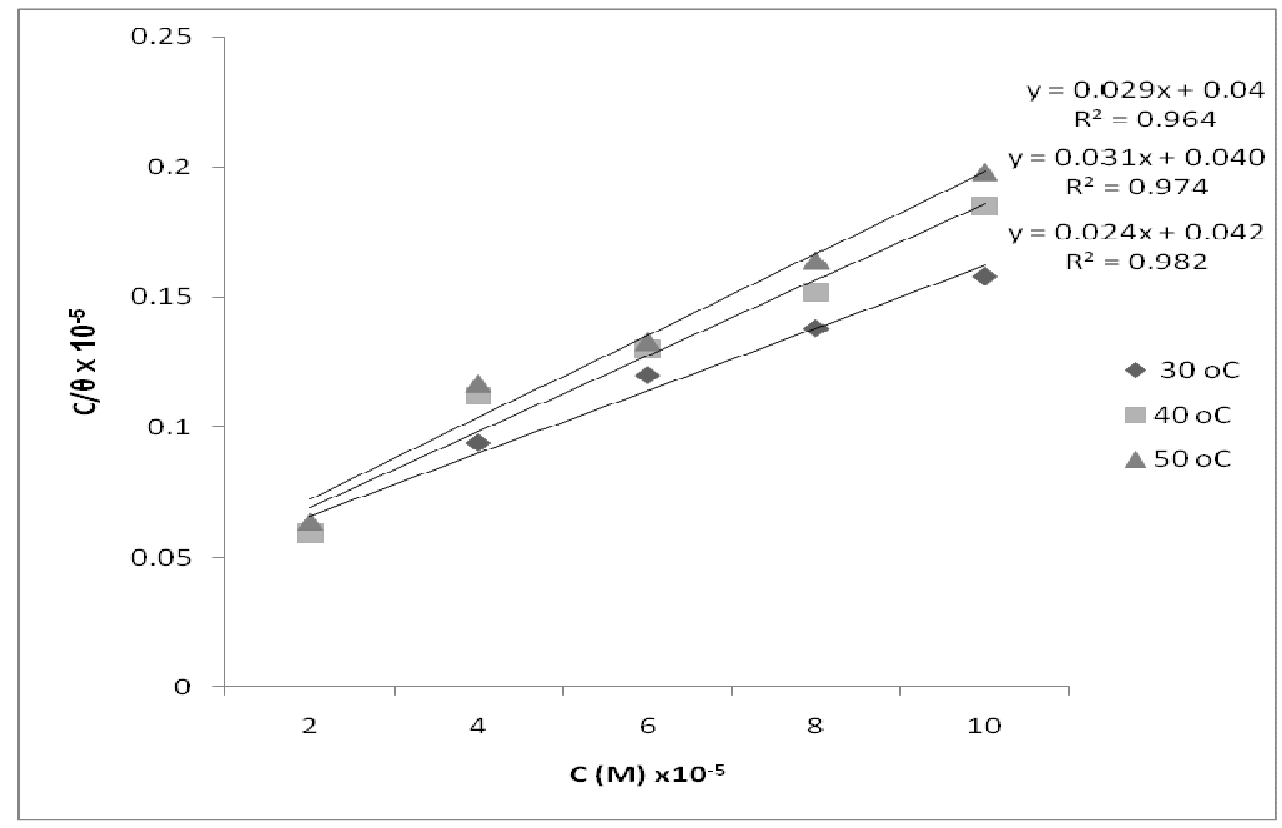

Figure 3. Langmuir adsorption isotherm plot for nizoral $+\mathrm{KI}$ at 30,40 and $50{ }^{\circ} \mathrm{C}$. 
The thermodynamic- kinetic model of El-Awady et al. is given by [2]:

$$
\log \frac{\theta}{1-\theta}=\log K+y \log C
$$

where $\mathrm{C}$ is the concentration of the inhibitor and $\theta$ is the surface coverage. $\mathrm{K}$ is a constant related to the equilibrium constant of adsorption process $\left(\mathrm{K}_{\mathrm{ads}}\right)$ as $\mathrm{K}_{\mathrm{ads}}=$ $\mathrm{K}^{1 / \mathrm{y}} .1 / \mathrm{y}$ is the number of inhibitor molecules occupying one active site (or the number of water molecules replaced by one molecule of NZR). Curve fitting of the data to the thermodynamic-kinetic model is shown in Fig. 4. These data gave straight lines with $\mathrm{R}^{2}>0.9$ for NZR and NZR + 0.005 M KI mixture. The values of $1 / \mathrm{y}$ and $\mathrm{K}_{\mathrm{ad}}$ calculated from the El-Awady model curve are given in Table 3 . The values of $1 / \mathrm{y}$ obtained are more than unity indicating that each molecule of NZR involved in the adsorption process is attached to more than one active site on the metal surface [10].

(a)

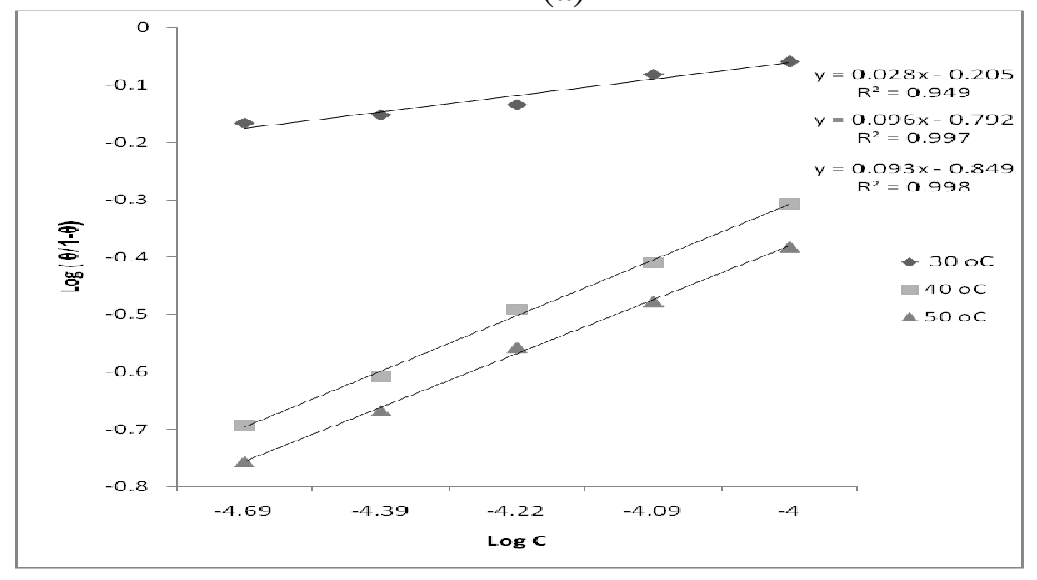

(b)

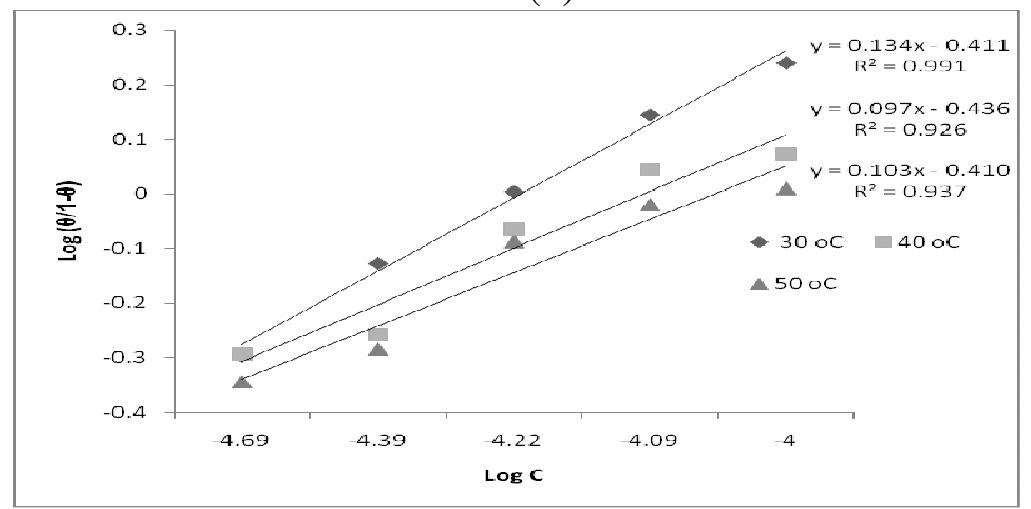

Figure 4. El-Awady et al. isotherm plot for (a) nizoral and (b) nizoral $+\mathrm{KI}$ at different temperatures.

All the values of $\mathrm{K}_{\mathrm{ad}}$ are low which suggests weak interactions (physisorption) of the systems studied on the mild steel surface [48]. 
Table 3. Some parameters of the linear regression from Langmuir and El-Awady adsorption isotherm.

\begin{tabular}{|c|c|c|c|c|c|c|c|c|c|}
\hline \multirow{2}{*}{ Inhibitor } & \multirow{2}{*}{$\begin{array}{c}\text { Temperature } \\
\left({ }^{\circ} \mathrm{C}\right)\end{array}$} & \multicolumn{4}{|c|}{ Langmuir isotherm } & \multicolumn{4}{|c|}{ El-Awady isotherm } \\
\hline & & $\mathrm{K}_{\mathrm{ads}}$ & $\Delta G_{a d z}^{o}$ & Slope & $\mathrm{R}^{2}$ & $\mathrm{~K}_{\mathrm{ads}}$ & $\Delta G_{a d z}^{o}$ & $1 / y$ & $\mathrm{R}^{2}$ \\
\hline \multirow[t]{2}{*}{ NZR } & 30 & 83.33 & -21.26 & 0.041 & 0.995 & 20.84 & -11.31 & 35.71 & 0.949 \\
\hline & 40 & 10.42 & -16.55 & 0.045 & 0.937 & 17.78 & -15.19 & 10.42 & 0.997 \\
\hline \multirow{4}{*}{$\mathrm{NZR}+\mathrm{KI}$} & 50 & 9.35 & -12.78 & 0.050 & 0.937 & 13.46 & -16.04 & 10.75 & 0.998 \\
\hline & 30 & 23.81 & -18.10 & 0.024 & 0.982 & 11.66 & -12.50 & 7.46 & 0.991 \\
\hline & 40 & 25.00 & -18.82 & 0.029 & 0.964 & 95.51 & -12.91 & 9.71 & 0.937 \\
\hline & 50 & 25.00 & -19.43 & 0.031 & 0.974 & 31.24 & -13.48 & 10.31 & 0.926 \\
\hline
\end{tabular}

The free energy of adsorption is related to the equilibrium constant of adsorption $\mathrm{K}$ by the following equation:

$$
K=\frac{1}{55.5} \exp \left[\frac{-\Delta G_{a d s}^{o}}{R T}\right]
$$

The value 55.5 in the above equation is the concentration of water in solution in $\mathrm{mol} \mathrm{L} \mathrm{L}^{-1}$.

The values of free energy of adsorption, $\Delta G_{a d s}^{o}$, for NZR in the temperature range 30-50 ${ }^{\circ} \mathrm{C}$ are shown in Table 3 . The negative values indicate spontaneous adsorption and the stability of the inhibitor on the metal surface [43]. The values of $\Delta G_{a d s}^{o}$, indicate that the inhibitor functions by physically adsorbing on the surface of the mild steel. Generally values of $\Delta G_{a d s}^{\sigma}$ up to $-20 \mathrm{kJmol}^{-1}$ are consistent with electrostatic interaction between charged molecules and a charged metal (which indicates physisorption), while those more negative than $40 \mathrm{kJmol}^{-1}$ involve charge sharing or transfer from the inhibitor molecules to the metal surface to form a co-ordinate type of bond (which indicates chemisorptions) [33]. Physical adsorption is as a result of electrostatic attraction between charged metal surface and charged species in the bulk of the solution. Adsorption of negatively charged species can also protect the positively charged metal surface acting with a negatively charged intermediate such as acid anions adsorbed on the metal surface [34].

\section{Effect of temperature}

In order to study the effect of temperature on the corrosion inhibition of mild steel in the acid medium and to determine the activation energy of the corrosion 
process, gravimetric studies were done at various temperatures $\left(30-50{ }^{\circ} \mathrm{C}\right)$ in the presence of different concentrations of NZR alone and in combination with KI. The corresponding results are given in Table 2. We note that increasing temperature increases corrosion rate and decreases inhibition efficiency at all the concentrations studied. According to Dehri and Ozcan [44], the relationship between the temperature dependence of percent inhibition efficiency (IE \%) of an inhibitor and the activation energy found in its presence was given as follows: (a) for the inhibitors whose IE\% decreases with temperature increasing, the value of activation energy $\left(\mathrm{E}_{\mathrm{a}}\right)$ found is greater than that in the uninhibited solution; (b) for the inhibitors whose IE\% does not change with temperature variation, the activation energy $\left(\mathrm{E}_{\mathrm{a}}\right)$ does not change with the presence or absence of inhibitors; (c) for the inhibitors whose IE\% increases with temperature increasing, the value of activation energy $\left(E_{a}\right)$ found is less than that in the inhibited solution.

The activation energies $\mathrm{E}_{\mathrm{a}}$ for mild steel in $0.1 \mathrm{M} \mathrm{H}_{2} \mathrm{SO}_{4}$ in the absence and presence of inhibitor were calculated from the integrated form of the Arrhenius equation:

$$
\log \frac{W_{2}}{W_{1}}=\frac{E_{a}}{2.303 R}\left(\frac{1}{T_{1}}-\frac{1}{T_{2}}\right)
$$

where $W_{2}$ and $W_{1}$ are the corrosion rates at temperature $\mathrm{T}_{1}$ and $\mathrm{T}_{2}$, respectively, and $\mathrm{R}$ the molar gas constant. An estimate of heat of adsorption was obtained from the trend of surface coverage with temperature, as follows :

$$
Q_{a d s}=2.303 R\left[\log \left(\frac{\theta_{2}}{1-\theta_{2}}\right)-\log \left(\frac{\theta_{1}}{1-\theta_{1}}\right)\right] x\left(\frac{T_{1 X} T_{2}}{T_{2}-T_{1}}\right) k J m o l^{-1}
$$

where $\theta_{1}$ and $\theta_{2}$ are the degrees of surface coverage at temperatures $\mathrm{T}_{1}$ and $\mathrm{T}_{2}$, respectively. The calculated values for both parameters are given in Table 4.

Increased activation energy $\left(E_{a}\right)$ in inhibited solutions compared to the blank suggests that the inhibitor is physically adsorbed on the corroding metal surface while either unchanged or lower $E_{a}$ in the presence of inhibitor suggest chemisorptions [45]. It is seen from Table 4 that $E_{a}$ values were higher in the presence of the additives compared to those in their absence, hence leading to reduction in the corrosion rates. This type of behavior as opined by Abd El Rehim et al. [46] and corroborated by Gomma and Wahdan [47] indicates that the inhibitor retards corrosion at ordinary temperature, while the inhibition efficiency is considerably diminished at higher temperatures. Since corrosion primarily occurs at surface sites free of adsorbed inhibitor molecules, the higher activation energies in the presence of NZR and NZR + KI mixtures can be attributed to the decrease in surface area available for corrosion. This observed variation of activation energy with inhibition efficiency according to Oguzie et al. [39], suggests that the inhibition process is activation controlled. 
Table 4. Calculated values of activation energy $\left(\mathrm{E}_{\mathrm{a}}\right)$ and heat of adsorption $\left(Q_{a d s}\right)$ for mild steel dissolution in $0.1 \mathrm{M} \mathrm{H}_{2} \mathrm{SO}_{4}$ in the absence and presence of NZR and NZR + $\mathrm{KI}$ at 30 and $50{ }^{\circ} \mathrm{C}$.

\begin{tabular}{lcc}
\hline System/concentration & $\mathrm{E}_{\mathrm{a}}\left(\mathrm{kJmol}^{-1}\right)$ & $Q_{a d s}\left(\mathrm{kJmol}^{-1}\right)$ \\
\hline Blank & 19.95 & - \\
$1 \times 10^{-4} \mathrm{M}$ NZR & 31.33 & -30.31 \\
$2 \times 10^{-5} \mathrm{M} \mathrm{NZR}+\mathrm{KI}$ & 21.36 & -4.24 \\
$4 \times 10^{-5} \mathrm{M} \mathrm{NZR}+\mathrm{KI}$ & 25.57 & -14.66 \\
$6 \times 10^{-5} \mathrm{M}$ NZR+ KI & 23.94 & -8.48 \\
$8 \times 10^{-5} \mathrm{M}$ NZR + KI & 28.12 & -15.25 \\
$1 \times 10^{-4} \mathrm{M}$ NZR + KI & 32.55 & -21.38 \\
\hline
\end{tabular}

The low and negative $\mathrm{Q}_{\mathrm{ads}}$ values indicate that the degree of surface coverage decreased with rise in temperature, supporting the earlier proposed physisorption mechanism [38]. Two processes govern this adsorption at particular temperatures: (i) ion pair adsorption between protonated molecules and the negatively charged metal surface, and (ii) interaction between the lone pair of electrons on nitrogen and oxygen atoms with the vacant orbital of metal atom. This act of inhibition at elevated temperature according to Dubey and Singh [36] is hindered by two processes: (i) time lag between the processes of adsorption or desorption becoming shorter at higher temperatures, and hence the metal is more exposed to acid solution, and (ii) the molecular films start acting as proton carrier and the molecules and the film get deprotonated, and thus it leads to desorption, and therefore this enhanced rate of corrosion results.

\section{Effect of iodide ions addition}

Synergism has become one of the most important effects in inhibition process and serves as basis for all modern corrosion inhibition formulation [48]. Interestingly, the addition of iodide ions has been observed to increase the adsorption of organic cations and this can greatly enhance the inhibition action of an organic compound in acid environment [49-51]. It is thought that the iodide ions are able to improve adsorption of the organic cations by forming intermediate bridges between the positively charged metal surface and the positive end of the organic inhibitor.

All the experimental results have shown that the addition of iodide ion to the inhibited solution increases the inhibition efficiency and the degree of surface coverage (Table 2). This behavior is attributed to the synergistic effect between added iodide ions and NZR. Schmitt and Bedhur [52] have considered the synergistic effect by proposing two types of co-adsorption, namely competitive and co-operative. In competitive adsorption the anion and cation are adsorbed at different sites on the metal surface. In co-operative adsorption, the anion is chemisorbed on the surface and the cation is adsorbed on a layer of the anion. According to Oguzie [38], two possible mechanisms account for the adsorption 
of the cations and anions (as ion-pairs) on the metal surface. As explained in the first mechanism, the ion-pairs are formed in the bulk of the solution and then adsorbed from the solution on to the metal surface as follows:

$$
\begin{aligned}
& \mathrm{Y}_{\mathrm{s}}+\mathrm{X}_{\mathrm{s}} \rightarrow(\mathrm{YX})_{\mathrm{s}} \\
& (\mathrm{YX})_{\mathrm{s}} \rightarrow(\mathrm{YX})_{\mathrm{ads}}
\end{aligned}
$$

In the second mechanism, the halide ion is first adsorbed on the metal surface and the inhibitor is then drawn into the double layer by the adsorbed halide ion in such a way that the ion-pair formation occurs directly on the metal surface:

$$
\begin{aligned}
& \mathrm{X}_{\mathrm{s}} \rightarrow \mathrm{X}_{\mathrm{ads}} \\
& \mathrm{Y}_{\mathrm{s}}+\mathrm{X}_{\mathrm{ads}} \rightarrow(\mathrm{YX})_{\mathrm{ads}}
\end{aligned}
$$

$Y_{s}, X_{s}$ and $(Y X)_{s}$ represent the inhibitor, halide ion and ion-pair, respectively, in the bulk of the solution, while $\mathrm{Y}_{\mathrm{ads}}, \mathrm{X}_{\mathrm{ads}}$ and $(\mathrm{YX})_{\mathrm{ads}}$ refer to the same specie in the adsorbed state.

To further prove the synergistic effect of the iodide ion addition in the presence of NZR, synergism parameter $S_{1}$, was evaluated using the relationship given by Aramaki and Hackerman and reported elsewhere [11, 33]:

$$
S_{1}=\frac{1-I_{1+2}}{1-I_{1+2}^{\prime}}
$$

where $I_{1+2}=\left(\mathrm{I}_{1}+\mathrm{I}_{2}\right) ; \quad \mathrm{I}_{1}=$ inhibition efficiency of the halides; $\mathrm{I}_{2}=$ inhibition efficiency of Nizoral; $I=$ measured inhibition efficiency for the Nizoral in combination with iodide ions. This parameter was evaluated from the inhibition efficiency values obtained from gravimetric measurements using Equ. (2). The results obtained are presented in Table 5. The $S_{1}$ values are greater than unity, suggesting that the enhanced inhibition efficiency resulting from the combination of NZR and iodide ion is only due to synergism. Similar results have been reported elsewhere $[48,53,54]$.

Table 5. Synergism parameter $\left(\mathrm{S}_{1}\right)$ for different concentrations of NZR at $30{ }^{\circ} \mathrm{C}$.

\begin{tabular}{|c|c|}
\hline Concentration of NZR & Synergism parameter, $\mathrm{S}_{1}$ \\
\hline $2 \times 10^{-5} \mathrm{M}$ & 2.12 \\
\hline $4 \times 10^{-5} \mathrm{M}$ & 1.90 \\
\hline $6 \times 10^{-5} \mathrm{M}$ & 1.58 \\
\hline $8 \times 10^{-5} \mathrm{M}$ & 1.46 \\
\hline $1 \times 10^{-4} \mathrm{M}$ & 1.45 \\
\hline
\end{tabular}




\section{Conclusions}

1. Nizoral (NZR) inhibits mild steel corrosion in sulphuric acid solution.

2. The inhibition efficiency increased with concentration but decreased with rise in temperature.

3. Synergistic effects between NZR and KI have been observed. The addition of $\mathrm{KI}$ enhances the inhibition efficiency significantly.

4. The adsorption of NZR, (NZR $+\mathrm{KI}$ ) on mild steel surface from $0.1 \mathrm{M} \mathrm{H}_{2} \mathrm{SO}_{4}$ obeys Langmuir adsorption isotherm and the kinetic/thermodynamic adsorption model of El-Awady et al. at all the concentrations and temperatures studied.

5. Phenomenon of physical adsorption is proposed from the values of kinetic/thermodynamic parameter $\left(\mathrm{Ea}, \Delta G_{a d s}^{o}\right)$ obtained.

6. The adsorption of NZR and (NZR $+\mathrm{KI})$ onto mild steel surface is a spontaneous process.

\section{References}

1. T. Hong, W.P. Jepson, Corros. Sci. 43 (2001) 1839.

2. S.A. Umoren, I.B. Obot, Surf. Rev. \& Lett. 15(3) (2008) 277.

3. U. Ergun, D. Yuzer, C. Emregul, Mater. Chem. \& Phys. 109 (2008) 492.

4. H. Ju, Y. Li, Corros Sci. 49 (2007) 4185.

5. G.Y. Elewady, I.A. El-Said, A.S. Fouda, Int. J. Electrochem. Sci. 3 (2008) 644.

6. W. Li, G. He, C. Pei, B. Hou, Electrochim. Acta 52 (2007) 6386.

7. I.B. Obot, N.O. Obi-Egbedi, S.A. Umoren, Corros. Sci. 51 (2009) 1869

8. M. Benabdellah, R. Touzani, A. Aouniti, A. Dafali, S. El-Kadiri, B. Hammouti, M. Benkaddour, Mater. Chem. \& Phys. 105 (2007) 373.

9. M. Lebrini, F. Bentiss, H. Vezin, M. Lagrenee, Corros. Sci. 48 (2006) 1279.

10. M. Bouklah, N. Benchat, B. Hammouti, A. Aouniti, S. Kertit, Mater. Lett. 60 (2006) 1901.

11. S.A. Umoren, I.B. Obot, E.E. Ebenso, E-Journal of Chemistry 5(2) (2008) 355.

12. G.K. Gomma, Asian J. Chem. 5(3) ( 1993) 761.

13. G.K. Gomma, Mater. Chem. \& Phys. 54 (1998) 241.

14. S.A. Umoren, O. Ogbobe, E.E. Ebenso, U.J. Ekpe, Pigment Resin Technol. 35 (3) (2006) 284.

15. I.B. Obot, N.O. Obi-Egbedi, S.A. Umoren, Corros. Sci. 51 (2009) 276.

16. M. Abdallah, Corros. Sci. 44 (2002) 728.

17. M. Abdallah, Corros. Sci. 46 (2004) 1996.

18. M.M. El-Naggar, Corros. Sci. 49 (2007) 2226.

19. A.S. Fouda, A.A. Al-Sarawy, F. Sh-Ahmed, H.M. El-Abbasy, Corros. Sci. 51(3) (2009) 485.

20. R. Solmaz, G. Kardas, B. Yazici, M. Erbil, Protection of Metals 41(6) (2005) 581.

21. E.E. Ebenso, N.O. Eddy, A.O. Odiongeyi , Port. Electrochimica Acta 27(1) (2009) 13. 
22. S.A. Odoemelam, E.C. Ogoko, B.N. Ita, N.O. Eddy, Port. Electrochimica Acta 27 (2009) 57.

23. T. Arslan, F. Kandemirli, E.E. Ebenso, I. Love, H. Alemu, Corros. Sci. 51 (2009) 35.

24. S.K. Shukla, A.K. Singh, I. Ahmed, M.A. Quraishi, Mater. Lett. 63 (2009) 819.

25. N.O. Eddy, U.J. Ibok, E.E. Ebenso, A. El Nemr, E.S.H. El Ashry, J. Mol. Mod. (2009) doi: 10.1007/s 00894 - 009 - 04 - 72 - 7).

26. I.B. Obot, N.O. Obi-Egbedi, Colloids \& Surf. A. Physico.\& Engr. Asp. 330 (2-3) (2008) 207.

27. E.E. Ebenso, T. Arslan, F. Kandemirli, N. Caner, I. Love, Int. J. Quantum Chem (2009) Quantum chemical studies of some rhodanine azosulpha drugs as corrosion inhibitors for mild steel in acidic medium (in press).

28. N.O. Eddy, S.A. Odoemelam, J. Mat. Sci. 4 (2008) 87.

29. N.O. Eddy, S.A. Odoemelam, P. Ekwumengbo, Sci. Res. Essays 4(1) (2009) 33.

30. N.O. Eddy, S.A. Odoemelam, A.J. Mbaba, Afri. J. Pure \& Appl. Chem 2(12) (2008) 132.

31. S.K. Shukla, M.A. Quraishi, J. Appl. Electrochem. (2009) doi: 10.1007/s 10800-009-9834-1.

32. M.N. Mousa, A.S. Fouda, F.I. Taha, A. Elnenna, Bull. Korean Chem. Soc. 9(4) (1988) 191.

33. S.A. Umoren, E.E. Ebenso, Mater. Chem. \& Phys. 106 (2007) 387.

34. S.A. Umoren, I.B. Obot, E.E. Ebenso, N.O. Obi-Egbedi, Int. J. Electrochem. Sci. 3 (2008) 1029.

35. E.E. Oguzie, E.E. Ebenso, Pigment Resin Technol. 35 (2006) 30.

36. A.K. Dubey, G. Singh, Portugaliae Electrochimica Acta. 25(2007) 249.

37. N. Hackerman, E. Snavely Jr., J.S. Payne, J. Electrochem. Soc. 113 (1966) 651.

38. E.E. Oguzie, Corros. Sci. 49 (2007) 1527.

39. E.E. Oguzie, B.N. Okolue, E.E. Ebenso, G.N. Onuoha, A.I. Onuchukwu, Mater. Chem. \& Phys. 87 (2004) 394.

40. J. O’M. Bockris, D. Drazic, Electrochim. Acta 7 (1962) 293.

41. M.A. Quraishi, J. Rawat, M. Ajmal, J. Appl. Electrochem. 30 (2000) 745.

42. M. Behpour, S.M. Ghoreishi, N. Soltani, M. Salavati-Niasari, M. Hamadanian, A. Gandomi, Corros. Sci. 50 (2008) 2172.

43. M. Bouklah, B. Hammouti, M. Lagrenee, F. Bentiss, Corros. Sci. 48 (2006) 2831.

44. I. Dehri, M. Ozcan, Mater. Chem. \& Phys. 98 (2006) 316.

45. A.S. Fouda, A.A. Al. Sarawy, E.E. El. Katori, Desalination 201 (2006) 1.

46. S.S. Abd El Rehim, M.A.M. Ibrahim, K.F. Khalid, Mater. Chem. Phys. 70 (2001) 270.

47. G.K. Gomma, M.H. Wahdan, Bull. Chem. Soc. Jpn. 67 (1994) 5.

48. S.A. Umoren, E.E. Ebenso, Pigment Resin Technol. 37(3) (2008) 173.

49. L. Larabi, Y. Harek, Portugaliae Electrochimica Acta 22 (2004) 227. 
50. L. Larabi, Y. Harek, M. Traisnel, A. Mansri, J. Appl. Electrochem. 34 (2004) 833.

51. M. Abdallah, E.A. Helal, A.S. Fouda, Corros. Sci. 48 (7) (2006) 1639.

52. G. Schmitt, K. Bedhur, Werkst. Korros. 36 (1985) 273.

53. S.A. Umoren, O. Ogbobe, E.E. Ebenso, Bull. Electrochem. 22(4) (2006) 155.

54. Y. Feng, K.S. Siow, W.K. Teo, A.K. Hsieh, Corros. Sci. 41 (1999) 829. 